\title{
Incidence of inflammatory bowel disease across Europe: is there a difference between north and south? Results of the European collaborative study on inflammatory bowel disease (EC-IBD)
}

S Shivananda, J Lennard-Jones, R Logan, N Fear, A Price, L Carpenter, $M$ van Blankenstein, and the EC-IBD Study Group (see appendix for committees, participants, and addresses)

\begin{abstract}
Background-It has been suggested that the incidence of inflammatory bowel disease (IBD), which includes ulcerative colitis (UC) and Crohn's disease (CD), is three or more times higher in northern than in southern Europe. The aim of this EC funded study was to investigage this apparent variation by ascertaining the incidence of IBD across Europe.

Methods-For the period 1 October 1991 to 30 September 1993 all new patients diagnosed with IBD were prospectively identified in 20 European centres according to a standard protocol for case ascertainment and definition.
\end{abstract}

Findings-Altogether 2201 patients aged 15 years or more were identified, of whom 1379 were diagnosed as UC (including proctitis), 706 as $C D$, and 116 as indeterminate. The overall incidence per 100000 at ages 15-64 years (standardised for age and sex) of UC was $10.4(95 \%$ confidence interval $(95 \% \mathrm{CI}) 7.6$ to $13 \cdot 1)$ and that of CD was $5 \cdot 6(95 \%$ CI $2 \cdot 8$ to $8 \cdot 3)$. Rates of UC in northern centres were $40 \%$ higher than those in the south (rate ratio $(R R)=1.4(95 \%$ CI 1.2 to $1 \cdot 5))$ and for CD they were $80 \%$ higher $(R R=1.8(95 \%$ CI 1.5 to $2 \cdot 1)$ ). For UC the highest reported incidence was in Iceland $(24 \cdot 5,95 \%$ CI $17 \cdot 4$ to $31 \cdot 5$ ) and for CD, Maastricht (The Netherlands; $9 \cdot 2,95 \%$ CI 6.5 to $11 \cdot 8)$ and Amiens (north west France; 9.2, 95\% CI $6 \cdot 3$ to $12 \cdot 2)$. The lowest incidence of UC was in Almada (southern Portugal) (1.6, $95 \% \mathrm{CI} 0.0$ to $3 \cdot 2$ ) and of $\mathrm{CD}$ in Ioannina (north west Greece) $(0.9,95 \%$ CI 0.0 to $2 \cdot 2)$. An unexpected finding was a difference in the age specific incidence of $U C$ in men and women with the incidence in women but not men declining with age.

Interpretation-The higher overall incidence rates in northern centres did not seem to be explained by differences in tobacco consumption or education. Nevertheless, the magnitude of the observed excess for both conditions is less than expected on the basis of previous studies. This may reflect recent increases in the incidence of IBD in southern Europe whereas those in the north may have stabilised.

(Gut 1996; 39: 690-697)
Keywords: Crohn's disease, ulcerative colitis, epidemiology.

Ulcerative colitis (UC) and Crohn's disease (CD) are chronic inflammatory bowel diseases (IBDs) of unknown aetiology. Previous studies have suggested that the incidence of these diseases may vary greatly across Europe, with higher rates being found in the north than the south. ${ }^{1-19}$ For example, the incidence of UC found in Copenhagen, Denmark (8.1 per 100000 ) was four times that in Bologna, Italy $(1.9$ per 100000$) .^{25}$ For CD, the rate of $4 \cdot 1$ per 100000 in Copenhagen was five times that in Galicia, north west Spain $(0.8$ per $100000) .{ }^{58}$ Such patterns could be due to different study designs (for example, criteria for case definition, methods of case ascertainment, or the time period of investigation) or they could represent real differences which might reflect environmental factors, lifestyle, or genetic susceptibility.

In 1988, around 50 European gastroenterologists and other experts attended a meeting in Rotterdam to plan a study to investigate these patterns. ${ }^{20}$ The primary aim of the resultant EC-IBD study was to measure the incidence of $\mathrm{UC}$ and $\mathrm{CD}$ in centres in the north and south of Europe prospectively using a standard protocol for case ascertainment and data analysis. We report here the epidemiological findings for the two year study period 1 October 1991 to 30 September 1993.

\section{Methods}

\section{IDENTIFICATION OF STUDY CENTRES}

Potential participating centres for the study were identified at the Rotterdam meeting and from enquiries resulting from an announcement in the Lancet. $^{21}$ Investigators interested in participating were invited to take part if their centre satisfied the following requirements: firstly, the centre had a defined catchment area with up to date population data; secondly, diagnostic facilities for high quality endoscopy, radiology, and pathology were available in the catchment area; thirdly, the centre was part of a healthcare system which offered universal cover for primary and specialist services with an established system for referral from primary to secondary care.
Maastricht,

MEMIC-P.Debyeplein 1, 6200 MD Maastrich The Netherlands.

Accepted for publication 11 June 1996 
The study aimed to include centres across Europe. From northern Europe, the study areas comprised all of Iceland, south east Norway (including Oslo), Copenhagen County (Denmark), Eastern Health Board, Ireland (including Dublin), City of Leicester (United Kingdom), South Limburg including Maastricht (The Netherlands), Cities of Essen and Mülheim/Ruhr area (Germany), and the Department of Somme including Amiens (north west France). In the south, study areas comprised Unita' Sanitaria Locale 1 including Varese (northern Italy), Unita' Sanitaria Locale 51 and 53 including Crema and Cremona (northern Italy), Reggio Emilia (northern Italy), metropolitan Florence (central Italy), Vigo health area (north west Spain), Sabadell health area (north east Spain), District of Braga (northern Portugal), Ioannina, (north west Greece), Almada, Seixal, Sesimbra (southern Portugal), Palermo (Sicily, southern Italy), Heraklion (Crete, Greece), and Beer Sheva (Israel).

\section{CASE DEFINITION}

Diagnosis of IBD was on the basis of endoscopic or radiological evidence, or both, supported whenever possible by mucosal biopsy or examination of a specimen from operation. UC was defined as continuous mucosal inflammation without granulomata (by biopsy), affecting the rectum and some or all of the colon in continuity with the rectum (by endoscopy or radiology). Proctitis was defined as macroscopic inflammation with a clearly marked upper border within $15 \mathrm{~cm}$ of the anal margin and for the purposes of this report was classified with more extensive UC. $\mathrm{CD}$ was defined by both macroscopic and microscopic features using the Lennard-Jones criteria. ${ }^{22} \mathrm{~A}$ diagnosis of indeterminate colitis was used when there was clear evidence of IBD but insufficient evidence to make a definitive diagnosis of either UC or CD.

Incident cases were defined as all new cases which met the standard diagnostic definition (with probable or definite diagnosis) who were diagnosed between 1 October 1991 and 30 September 1993 in the resident population of the defined study areas. The date of diagnosis (taken as the date the patient was informed of the diagnosis) was used for the analysis of incidence of disease. Asymptomatic cases and cases detected as a result of any screening activities were excluded.

\section{CASE ASCERTAINMENT}

For each participating study centre, all general practitioners and hospital and medical specialists working in the field of gastroenterology were informed of the study. They were asked to identify all new patients seen during the study period with symptoms of persistent or relapsing diarrhoea or blood or mucus in their stools for more than three weeks or abdominal pain and weight loss without evident cause. To achieve as complete an ascertainment of incident cases as possible, investigators in each centre regularly canvassed general practitioners and relevant specialists both within and in the periphery of the study area by post, telephone, or personal visit. Exact methods of case finding varied between centres. These included regular searches of endoscopic, radiological, and pathological records and sometimes reports by pharmacists of prescriptions issued for drugs used to treat IBD. Patient self help groups were contacted and doctors were regularly reminded of the study at local medical meetings and in local medical newsletters.

\section{DATA COLLECTION}

To achieve consistency of methods between centres, two initial meetings of investigators from all centres, and three follow up meetings during the study period, were held. Most centres formed multidisciplinary teams to review the diagnostic and epidemiological data before recording them on the incidence data form. An external review team visited Greek, Iberian, Italian, and Scandinavian groups for regional case reviews and the principal Investigator (SS) went on 'site visits' to all but one of the centres to review the local study protocol, the case ascertainment procedures, and the quality of data recorded on the incidence data form and, when necessary, suggested improvements. Each incidence data form had a unique identifying number and contained a patient consent form. Patient data were collected on sociodemographic characteristics, educational attainment, current occupation, smoking habits, oral contraceptive use, main symptoms and their duration, endoscopic and radiographical investigations, biopsies taken and histological abnormalities, and any surgery performed. On the basis of the initial investigations the diagnosis was recorded as UC, CD, proctitis only, indeterminate IBD, or other. One copy of the data form was then sent to Rotterdam for data processing. One year after diagnosis the data form was updated with the addition of data referring to any changes in diagnosis, disease extent, further surgery, and drug use for IBD in that year and sent to Rotterdam.

STATISTICAL ANALYSIS

Age, sex, and disease specific incidence rates (per 100000) for each study area were calculated by dividing the numbers of new cases in each category of age and sex by the corresponding estimated numbers of personyears at risk based on the population statistics for each area. Children and adolescents under the age of 15 were excluded as there were doubts about completeness of ascertainment in this age group in some centres.

Centre specific direct age and sex standardised incidence rates were obtained by applying the age specific rates to the European Standard Population ${ }^{23}$ using 10 year age groups (15-25, 25-34, 35-44, 45-54, 55-64). Approximate $95 \%$ confidence intervals $(95 \%$ CIs) were derived from the standard error for 
the logarithm of the directly standardised rate. ${ }^{24}$ Data for patients aged over 64 were excluded from calculation of the directly standardised rates due to the problems associated with completeness of case ascertainment among the oldest members of the population and because age specific population counts were not available for older ages in all centres.

To examine the hypothesis of a north-south difference in the incidence of IBD, age adjusted rate ratios (RRs) for northern centres relative to those in the south were estimated by the method of maximum likelihood. This involved fitting a log linear model to the centre, age, and sex specific cases and person-years using the EGRET computer package. ${ }^{25}$ Approximate $\chi^{2}$ tests of significance were obtained from the likelihood ratio and $95 \%$ CIs from the standard errors of the model coefficients.

Because of previously documented higher rates of IBD in the immigrant population of Leicester, rates were provided separately for the immigrant and non-immigrant populations. ${ }^{26}$ For the other centre with a substantial number of immigrants (Beer Sheva), rates could not be calculated separately, as the necessary population data were not provided. Data for Beer Sheva and the immigrant population of Leicester were excluded from calculation of rate ratios for the northern versus southern centres.

Rate ratios for northern versus southern centres were also estimated with additional adjustment for national tobacco consumption (used as a proxy measure of smoking status) and tertiary education (used as a proxy measure for social class and access to health care). Data for these factors and Gross National Product (GNP) were obtained from the 1993 World Development Report. ${ }^{27}$ For tobacco consumption and tertiary education, three groups were formed, containing roughly equal numbers of centres in each category for the analysis (tertiles). Rate ratios adjusted for these factors were estimated by adding terms to represent their categorical effects to the above mentioned log linear models.

\section{Results}

During the two year study period a total of 2201 patients aged 15 years and older were diagnosed with IBD in the 20 centres (due to relocation of investigators in Dublin, cases were recruited during the first year only) with one year follow up forms available for $98 \%$ of patients by December 1994. Final diagnosis at one year follow up was UC (including proctitis) in 1379 cases (63\%), CD in 706 cases $(32 \%)$, and indeterminate colitis in the remaining $116(5 \%)$. The initial diagnosis was unchanged for 2119 (96\%) cases; 37 cases with an initial diagnosis of indeterminate colitis were changed to $\mathrm{UC}$, and 20 to $\mathrm{CD} ; 16$ cases initially diagnosed as $\mathrm{UC}$ were changed to $\mathrm{CD}$ and conversely nine were changed from $C D$ to UC. The diagnostic methods used for UC were endoscopy in $99 \%$ of cases, biopsy in $95 \%$, and radiology in $31 \%$; for $\mathrm{CD}$ the corresponding figures were endoscopy in $81 \%$ of cases, biopsy in $78 \%$, radiology in $71 \%$, and examination of a resection specimen in $16 \%$. Cases with a final diagnosis of indeterminate colitis are not considered further.

Analysis of the diagnostic methods used, anatomical site, and extent of disease showed little overall difference between centres in the north and south of Europe (data not shown). Likewise, analysis of the presenting symptoms such as bowel frequency, occurrence of rectal bleeding, weight loss, and abdominal pain suggested no systematic differences in severity of symptoms at presentation between cases in the northern and southern centres.

\section{INCIDENCE BY AGE AND SEX}

Figure 1 shows the age specific incidence rates (per 100000 ) for UC including proctitis and CD for all 20 centres combined. For UC, different patterns of incidence were observed for men and women aged 35 and over, with the rates for men remaining fairly constant with increasing age, whereas those for women decreased. Incidence rates for $C D$ were generally lower and were broadly similar for men and women, with rates for both sexes declining with increasing age.

Tables I and II show the age and sex specific incidence for UC and CD for each study centre with centres ordered according to degree latitude. Some centre specific rates (for both $\mathrm{UC}$ and $\mathrm{CD}$ ) were based on very few cases and for some centres no cases were observed in certain age groups, particularly in the oldest age group (65+ years) for women.

Tables III and IV show the crude and age and sex adjusted incidence rates for ages 15 to 64 , for UC and CD, according to study centre. In general, the crude rates were similar to the age and sex adjusted rates. For both diagnostic groups there seemed to be a large degree of
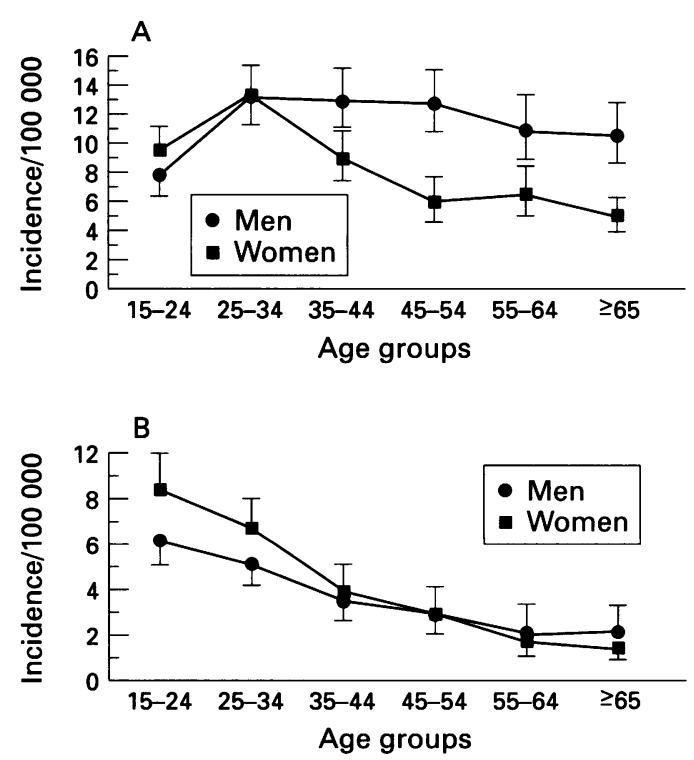

Figure 1: Age specific incidence rates per 100000 for ulcerative colitis including procolitis (UC) and Crohn's disease $(C D)$ in the 20 centres included in the EC-IBD study. 
TABLE I Incidence rates (/100 000) and numbers of cases (in parentheses) aged 15 years or over for ulcerative colitis (including proctitis) reported in the 20 centres included in the EC-IBD study, according to age and sex

\begin{tabular}{|c|c|c|c|c|c|c|c|}
\hline \multirow[b]{2}{*}{ Centre } & \multicolumn{3}{|l|}{ Men (age) } & \multicolumn{3}{|c|}{ Women (age) } & \multirow{2}{*}{$\begin{array}{l}\text { Total } \\
\geqslant 15\end{array}$} \\
\hline & $15-44$ & $45-64$ & $\geqslant 65$ & $15-44$ & $45-64$ & $\geqslant 65$ & \\
\hline \multirow{3}{*}{$\begin{array}{l}\text { Northern centres: } \\
\text { Reykjavik (Iceland) } \\
\text { Oslo (Norway) } \\
\text { Copenhagen (Denmark) } \\
\text { Dublin (Ireland) } \\
\text { Leicester (United Kingdom) } \\
\text { Non-immigrants } \\
\text { Immigrants } \\
\text { Maastricht (The Netherlands) } \\
\text { Essen (Germany) } \\
\text { Amiens (NW France) } \\
\text { All northern centres }\end{array}$} & $\begin{array}{r}27 \cdot 3(34) \\
18 \cdot 7(82) \\
8 \cdot 3(20) \\
16 \cdot 2(47)\end{array}$ & $\begin{array}{r}26 \cdot 4(12) \\
14 \cdot 1(27) \\
8 \cdot 3(11) \\
22 \cdot 0(23)\end{array}$ & $\begin{array}{l}32 \cdot 2(8) \\
22 \cdot 3(26) \\
10 \cdot 6(7) \\
22 \cdot 1(10)\end{array}$ & $\begin{array}{l}27 \cdot 5(33) \\
17.5(75) \\
11.4(27) \\
13.8(42)\end{array}$ & $\begin{array}{c}11 \cdot 1(5) \\
8 \cdot 7(18) \\
9 \cdot 7(14) \\
7 \cdot 1(8)\end{array}$ & $\begin{array}{c}9 \cdot 7(3) \\
9.9(23) \\
13.3(13) \\
9 \cdot 7(7)\end{array}$ & $\begin{array}{l}24 \cdot 3(95) \\
15 \cdot 6(251) \\
10 \cdot 0(92) \\
14 \cdot 8(137)\end{array}$ \\
\hline & $\begin{array}{c}10 \cdot 0(8) \\
8 \cdot 1(3) \\
15 \cdot 1(46) \\
3.5(12) \\
6.3(16)\end{array}$ & $\begin{array}{c}13 \cdot 5(5) \\
8 \cdot 8(1) \\
17 \cdot 1(26) \\
3 \cdot 2(7) \\
9 \cdot 6(10)\end{array}$ & $\begin{array}{r}9 \cdot 8(3) \\
28 \cdot 7(1) \\
8 \cdot 8(6) \\
4 \cdot 2(4) \\
(0)\end{array}$ & $\begin{array}{l}10 \cdot 9(9) \\
20.4(8) \\
14.3(42) \\
5.8(19) \\
5 \cdot 2(16)\end{array}$ & $\begin{array}{c}5 \cdot 1(2) \\
26 \cdot 2(3) \\
9 \cdot 2(14) \\
4 \cdot 0(9) \\
5 \cdot 5(6)\end{array}$ & $\begin{array}{c}4 \cdot 3(2) \\
(0) \\
5 \cdot 9(6) \\
4 \cdot 6(9) \\
1 \cdot 1(1)\end{array}$ & $\begin{array}{c}9 \cdot 2(29) \\
15 \cdot 1(16) \\
13 \cdot 1(140) \\
4 \cdot 3(60) \\
5 \cdot 6(49)\end{array}$ \\
\hline & $12 \cdot 7(268)$ & $12 \cdot 2(122)$ & $12 \cdot 7(65)$ & $13.0(271)$ & $7 \cdot 6(79)$ & $7 \cdot 3(64)$ & $11 \cdot 4(869)$ \\
\hline $\begin{array}{l}\text { Southern centres: } \\
\text { Milan-Varese (Italy) } \\
\text { Crema-Cremona (Italy) } \\
\text { Reggio Emilia (Italy) } \\
\text { Florence (Italy) } \\
\text { Vigo (NW Spain) } \\
\text { Sabadell (NE Spain) } \\
\text { Braga (N Portugal) } \\
\text { Ioannina (NW Greece) } \\
\text { Almada (S Portugal) } \\
\text { Palermo, Sicily (Italy) } \\
\text { Heraklion, Crete (Greece) } \\
\text { Beer Sheva (Israel) }\end{array}$ & $\begin{array}{l}15 \cdot 4(14) \\
6.0(9) \\
9 \cdot 3(17) \\
10 \cdot 3(26) \\
5.9(14) \\
11.4(20) \\
5 \cdot 8(7) \\
9.5(10) \\
1.5(2) \\
15.6(9) \\
19.2(18) \\
12.0(20)\end{array}$ & $\begin{array}{l}6 \cdot 1(3) \\
19 \cdot 7(15) \\
10 \cdot 2(11) \\
11 \cdot 4(18) \\
11.3(12) \\
14 \cdot 8(11) \\
6 \cdot 7(3) \\
5 \cdot 0(3) \\
1.4(1) \\
17.0(4) \\
35.5(18) \\
8 \cdot 6(4)\end{array}$ & $\begin{array}{l}28 \cdot 8(6) \\
3 \cdot 0(1) \\
2 \cdot 9(2) \\
11 \cdot 7(11) \\
8 \cdot 6(4) \\
12.6(4) \\
(0) \\
15 \cdot 4(5) \\
4.0(1) \\
(0) \\
10.1(3) \\
5 \cdot 3(1)\end{array}$ & $\begin{array}{l}6 \cdot 6(6) \\
8 \cdot 1(10) \\
9 \cdot 1(16) \\
7 \cdot 9(20) \\
9 \cdot 5(23) \\
8 \cdot 1(14) \\
8 \cdot 0(10) \\
11 \cdot 2(12) \\
0 \cdot 7(1) \\
7 \cdot 7(5) \\
12 \cdot 3(12) \\
6 \cdot 1(10)\end{array}$ & $\begin{array}{r}3.8(2) \\
2.5(2) \\
5.5(6) \\
4.6(8) \\
1.7(2) \\
3.9(3) \\
3.9(2) \\
7.6(5) \\
4.2(3) \\
2.9(1) \\
14.9(8) \\
9.9(5)\end{array}$ & $\begin{array}{l}8 \cdot 5(3) \\
3 \cdot 4(2) \\
4 \cdot 1(4) \\
2 \cdot 7(4) \\
3 \cdot 8(3) \\
(0) \\
(0) \\
(0) \\
(0) \\
(0) \\
2 \cdot 7(1) \\
(0)\end{array}$ & $\begin{array}{c}10 \cdot 0(34) \\
7 \cdot 5(39) \\
7.5(56) \\
8 \cdot 1(87) \\
7.0(58) \\
9.0(52) \\
5 \cdot 5(22) \\
8 \cdot 5(35) \\
1.7(8) \\
8 \cdot 5(19) \\
16.6(60) \\
8.5(40)\end{array}$ \\
\hline All southern centres & $9 \cdot 5(166)$ & $11.9(103)$ & $8 \cdot 6(38)$ & $7 \cdot 9$ (139) & $5 \cdot 0(47)$ & $2 \cdot 6(17)$ & $8 \cdot 0(510)$ \\
\hline All centres & $11 \cdot 2(434)$ & $12 \cdot 1(225)$ & $10 \cdot 8(103)$ & $10 \cdot 7(410)$ & $6.4(126)$ & $5 \cdot 3(81)$ & $9 \cdot 8(1379)$ \\
\hline
\end{tabular}

variation between the centre specific rates. For $\mathrm{UC}$, the age and sex adjusted rate ranged from 24.5 per 100000 in Iceland, to 1.6 per 100000 in Almada (southern Portugal). For CD, the highest rate was 9.2 per 100000 in both Amiens (north west France) and Maastricht (The Netherlands), and the lowest was 0.9 per 100000 in Ioannina (north west Greece).

INCIDENCE IN NORTHERN EUROPE VERSUS SOUTHERN EUROPE

The overall age and sex adjusted rate for UC in all northern European centres combined was $40 \%$ higher than that of all southern European centres and that for CD $80 \%$ higher (Table V).
For UC and CD there was some suggestion that the age adjusted RRs differed for the two sexes, with slightly higher RRs being found in men for UC and in women for CD $\left(\chi^{2}\right.$ for difference in $R R s=4.2,1 \mathrm{df}, \mathrm{p}=0.04$ for $\mathrm{UC}$ and $\chi^{2}$ for difference in $R R s=3.3,1 d f, p=0.07$ for CD).

Additional adjustment for both national tobacco consumption and tertiary education tended to reduce the estimated RRs (Table V). After adjustment for both tobacco consumption and tertiary education significantly increased rates in northern versus southern centres were still found for UC and CD in women and for both sexes combined, whereas for both conditions in men the difference in

TABLE II Incidence rates (/100 000) and numbers of cases (in parentheses) aged 15 years or over for Crohn's disease reported in the 20 centres included in the EC-IBD study, according to age and sex

\begin{tabular}{|c|c|c|c|c|c|c|c|}
\hline \multirow[b]{2}{*}{ Centre } & \multicolumn{3}{|l|}{ Men (age) } & \multicolumn{3}{|c|}{ Women (age) } & \multirow{2}{*}{$\begin{array}{l}\text { Total } \\
\geqslant 15\end{array}$} \\
\hline & $15-44$ & $45-64$ & $\geqslant 65$ & $15-44$ & $45-64$ & $\geqslant 65$ & \\
\hline $\begin{array}{l}\text { Northern centres: } \\
\text { Reykjavik (Iceland) } \\
\text { Oslo (Norway) } \\
\text { Copenhagen (Denmark) } \\
\text { Dublin (Ireland) } \\
\text { Leicester (United Kingdom) } \\
\text { Non-immigrants } \\
\text { Immigrants } \\
\text { Maastricht (The Netherlands) } \\
\text { Essen (Germany) } \\
\text { Amiens (NW France) }\end{array}$ & $\begin{array}{r}10 \cdot 4(13) \\
9 \cdot 8(43) \\
5 \cdot 4(13) \\
5 \cdot 5(16) \\
\\
2 \cdot 5(2) \\
5 \cdot 4(2) \\
10 \cdot 2(31) \\
4 \cdot 1(14) \\
8 \cdot 2(21)\end{array}$ & $\begin{array}{l}4 \cdot 4(2) \\
2 \cdot 6(5) \\
5 \cdot 3(7) \\
2 \cdot 9(3) \\
\\
(0) \\
17 \cdot 5(2) \\
4 \cdot 0(6) \\
1 \cdot 4(3) \\
7 \cdot 7(8)\end{array}$ & $\begin{array}{l}8 \cdot 0(2) \\
5 \cdot 1(6) \\
1 \cdot 5(1) \\
2 \cdot 2(1) \\
\\
(0) \\
(0) \\
(0) \\
3 \cdot 1(3) \\
1 \cdot 6(1)\end{array}$ & $\begin{array}{l}10 \cdot 0(12) \\
9 \cdot 6(41) \\
12 \cdot 2(29) \\
7 \cdot 9(24) \\
\\
9 \cdot 7(8)) \\
2 \cdot 5(1) \\
13 \cdot 9(41) \\
6 \cdot 7(22) \\
12 \cdot 8(32)\end{array}$ & $\begin{array}{l}2 \cdot 2(1) \\
5 \cdot 3(11) \\
3 \cdot 5(5) \\
2 \cdot 7(3) \\
\\
(0) \\
(0) \\
2 \cdot 6(4) \\
3 \cdot 1(7) \\
6 \cdot 4(7)\end{array}$ & $\begin{array}{l}(0) \\
(0) \\
(0) \\
(0) \\
2 \cdot 2(2)\end{array}$ & $\begin{array}{l}3 \cdot 2(10) \\
4 \cdot 7(5) \\
7 \cdot 7(82) \\
3 \cdot 5(49) \\
8 \cdot 1(71)\end{array}$ \\
\hline All northern centres & $7 \cdot 3(155)$ & $3 \cdot 6(36)$ & $2 \cdot 7(14)$ & $10 \cdot 1(210)$ & $3 \cdot 6(38)$ & $2 \cdot 8(24)$ & $6 \cdot 3(477)$ \\
\hline $\begin{array}{l}\text { Southern centres: } \\
\text { Milan-Varese (Italy) } \\
\text { Crema-Cremona (Italy) } \\
\text { Reggio Emilia (Italy) } \\
\text { Florence (Italy) } \\
\text { Vigo (NW Spain) } \\
\text { Sabadell (NE Spain) } \\
\text { Braga (N Portugal) } \\
\text { Ioannina (NW Greece) } \\
\text { Almada (S Portugal) } \\
\text { Palermo, Sicily (Italy) } \\
\text { Heraklion, Crete (Greece) } \\
\text { Beer Sheva (Israel) }\end{array}$ & $\begin{array}{l}1 \cdot 1(1) \\
0 \cdot 7(1) \\
5 \cdot 4(10) \\
3 \cdot 6(9) \\
9 \cdot 7(23) \\
5 \cdot 7(10) \\
3 \cdot 3(4) \\
1.0(1) \\
1.5(2) \\
10 \cdot 4(6) \\
7 \cdot 5(7) \\
1.8(3)\end{array}$ & $\begin{array}{l}2 \cdot 0(1) \\
5 \cdot 3(4) \\
3 \cdot 7(4) \\
0 \cdot 6(1) \\
3 \cdot 8(4) \\
(0) \\
2 \cdot 2(1) \\
1 \cdot 7(1) \\
2 \cdot 9(2) \\
(0) \\
7 \cdot 9(4) \\
4 \cdot 3(2)\end{array}$ & $\begin{array}{l}14 \cdot 4(3) \\
3 \cdot 0(1) \\
5 \cdot 9(4) \\
1 \cdot 1(1) \\
4 \cdot 3(2) \\
3 \cdot 2(1) \\
(0) \\
3 \cdot 1(1) \\
(0) \\
6 \cdot 4(1) \\
(0) \\
(0)\end{array}$ & $\begin{array}{l}5 \cdot 5(5) \\
4 \cdot 1(5) \\
5 \cdot 1(9) \\
4 \cdot 4(11) \\
4 \cdot 1(10) \\
7 \cdot 5(13) \\
7 \cdot 2(9) \\
0 \cdot 9(1) \\
3 \cdot 5(5) \\
7 \cdot 7(5) \\
3 \cdot 1(3) \\
6 \cdot 1(10)\end{array}$ & $\begin{array}{l}(0) \\
1 \cdot 2(1) \\
1 \cdot 8(2) \\
3 \cdot 4(6) \\
0 \cdot 9(1) \\
5 \cdot 2(4) \\
1 \cdot 9(1) \\
(0) \\
2 \cdot 8(2) \\
2 \cdot 9(1) \\
(0) \\
7 \cdot 9(4)\end{array}$ & $\begin{array}{l}2 \cdot 8(1) \\
3 \cdot 4(2) \\
1 \cdot 0(1) \\
0 \cdot 7(1) \\
(0) \\
(0) \\
(0) \\
(0) \\
(0) \\
(0) \\
(0) \\
4 \cdot 3(1)\end{array}$ & $\begin{array}{l}3 \cdot 2(11) \\
2 \cdot 7(14) \\
4 \cdot 0(30) \\
2 \cdot 7(29) \\
4 \cdot 8(40) \\
4 \cdot 9(28) \\
3 \cdot 7(15) \\
1 \cdot 0(4) \\
2 \cdot 3(11) \\
5 \cdot 8(13) \\
3 \cdot 9(14) \\
4 \cdot 3(20)\end{array}$ \\
\hline All southern centres & $4 \cdot 4(77)$ & $2 \cdot 8(24)$ & $3 \cdot 2(14)$ & $4.9(86)$ & $2 \cdot 3(22)$ & $0.9(6)$ & $3 \cdot 6(229)$ \\
\hline All centres & $6 \cdot 0(232)$ & $3 \cdot 2(60)$ & $2.9(28)$ & $7 \cdot 7(296)$ & $3.0(60)$ & $2 \cdot 0(30)$ & $5 \cdot 0(706)$ \\
\hline
\end{tabular}


TABLE III Incidence rates (/100 000) and numbers of cases aged 15-64 years for ulcerative colitis (including proctitis) reported in the 20 centres included in the EC-IBD study

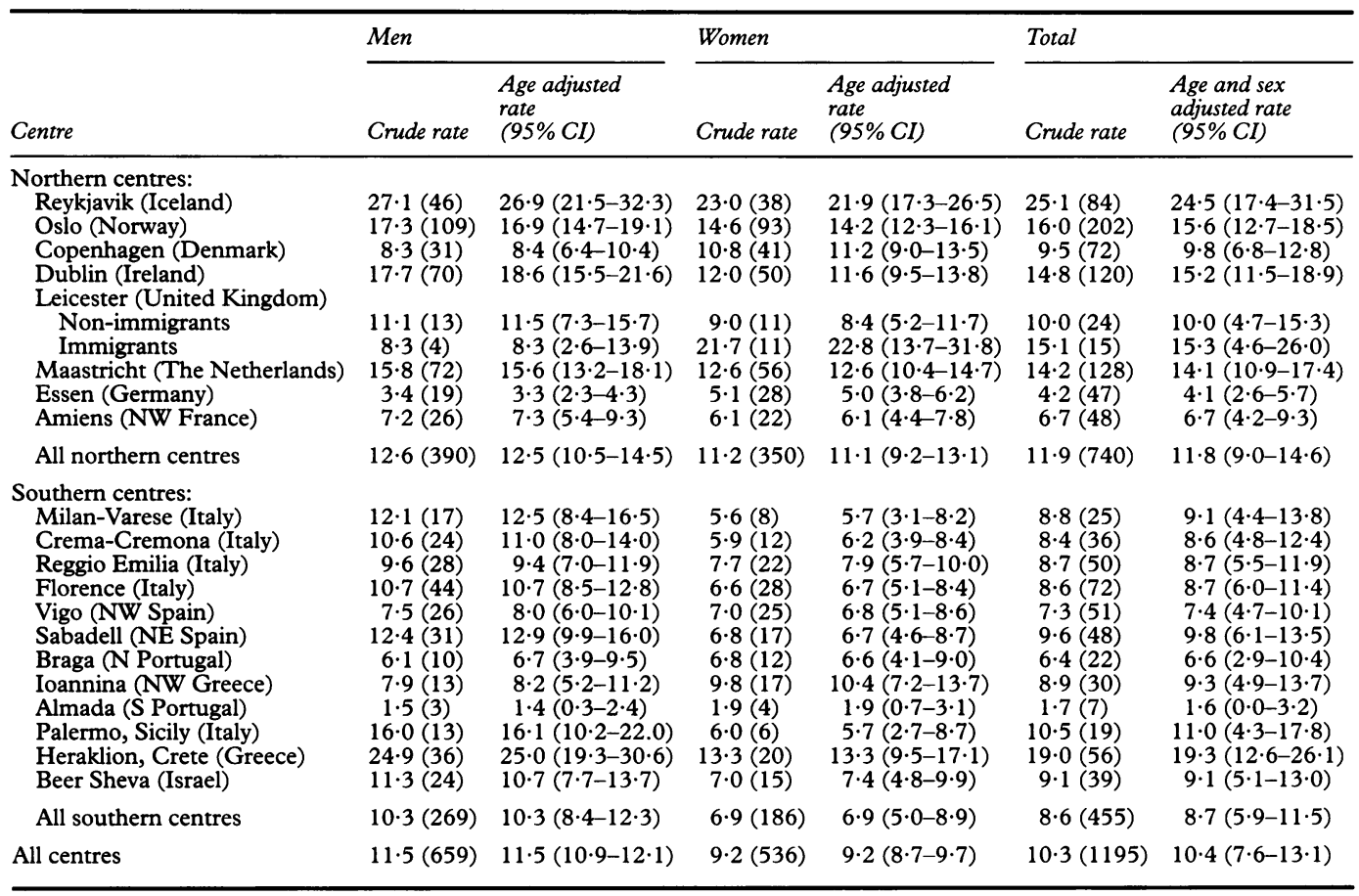

incidence of disease between the north and south of Europe was no longer statistically significant.

The relation between centre specific rates and GNP was examined. Northern centres tended to have higher rates of UC and CD and higher levels of GNP (Fig 2).

As a consequence of the strong relation between incidence of disease, GNP, and latitude, it was not possible to reliably estimate the relative incidence in northern versus southern centres independent of GNP.

\section{Discussion}

This is the first study to assess the incidence of UC and CD across Europe prospectively and simultaneously. The overall incidence per 100000 at ages $15-64$ years was $10 \cdot 4$ for UC and 5.6 for CD. Rates of UC in northern centres were $40 \%$ higher than those in the south ( $R R=1 \cdot 4,95 \%$ CI 1.2 to 1.5$)$ and for CD they were $80 \%$ higher $(R R=1 \cdot 8,95 \%$ CI 1.5 to $2 \cdot 1$ ). The observed excess in incidence of UC and CD in northern centres did not seem to be explained by differences in tobacco

TABLE IV Incidence rates (/100 000) and numbers of cases aged 15-64 years for Crohn's disease reported in the 20 centres included in the EC-IBD study

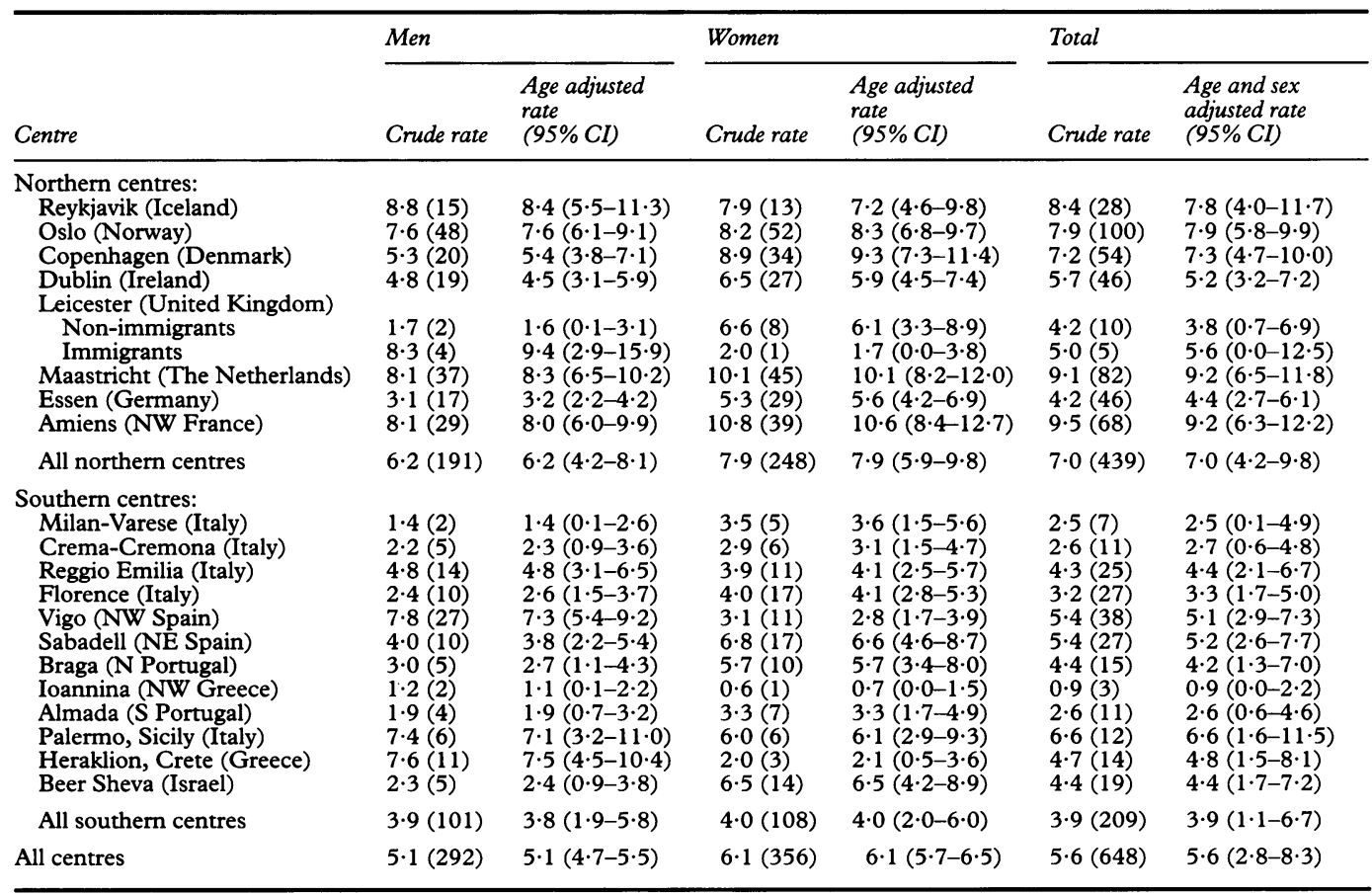


TABLE V Relative rates for northern European centres compared with southern European centres ${ }^{\star}, 95 \%$ CIs, and the corresponding $p$ value for ages $15-64$

\begin{tabular}{|c|c|c|c|c|c|c|}
\hline \multirow[b]{2}{*}{ Factors adjusted for } & \multicolumn{3}{|l|}{ Ulcerative colitis } & \multicolumn{3}{|l|}{ Crohn's disease } \\
\hline & Men & Women & Both sexes & Men & Women & Both sexes \\
\hline $\begin{array}{l}\text { Age and sex } \\
\text { p Value }\end{array}$ & $\begin{array}{l}1.23(1.05-1.44) \\
0.012\end{array}$ & $\begin{array}{l}1.57(1.30-1.88) \\
<0.001\end{array}$ & $\begin{array}{l}1.37(1 \cdot 21-1.55) \\
<0.001\end{array}$ & $\begin{array}{l}1.53(1.20-1.96) \\
<0.001\end{array}$ & $\begin{array}{l}2.09(1.65-2 \cdot 65) \\
<0.001\end{array}$ & $\begin{array}{l}1 \cdot 81(1 \cdot 53-2 \cdot 15) \\
<0.001\end{array}$ \\
\hline $\begin{array}{l}\text { Age, sext, tobacco consumption, } \\
\text { and tertiary education } \\
\text { p Value }\end{array}$ & $\begin{array}{l}1 \cdot 16(0 \cdot 95-1 \cdot 41) \\
0 \cdot 152\end{array}$ & $\begin{array}{l}1 \cdot 38(1 \cdot 10-1 \cdot 74) \\
0 \cdot 004\end{array}$ & $\begin{array}{l}1.26(1 \cdot 08-1 \cdot 46) \\
0.003\end{array}$ & $\begin{array}{l}1 \cdot 15(0.85-1 \cdot 55) \\
0.370\end{array}$ & $\begin{array}{l}2 \cdot 25(1.63-3.09) \\
<0.001\end{array}$ & $\begin{array}{l}1 \cdot 61(1 \cdot 30-2 \cdot 00) \\
<0 \cdot 001\end{array}$ \\
\hline
\end{tabular}

${ }^{\star}$ Data for Leicester include non-immigrant population only. Beer Sheva excluded from data for southern centres.

†Adjusted for sex when appropriate.

consumption and education, although the available data on these and other potential confounding factors were limited.

For both diseases, the observed excess incidence in northern centres is smaller than previously suggested. By contrast with earlier studies, the present study used agreed standard criteria for case definition, and a uniform approach and time period for case ascertainment, and a common protocol for data recording. In addition, the pooled data analysis allowed the application of standard methods of analysis, including the calculation of rates for specific age groups. Together, these factors may partly explain the smaller difference in incidence between northern and southern centres. The inclusion of a wide range of study centres is likely to have produced a more representative picture of IBD across Europe than previous comparisons that were based on a few selected centres.

Despite the relatively modest overall difference in incidence rates between northern and southern centres, there seems to be considerable variation in the incidence of both diseases across Europe. The most striking examples are the high incidence of UC in
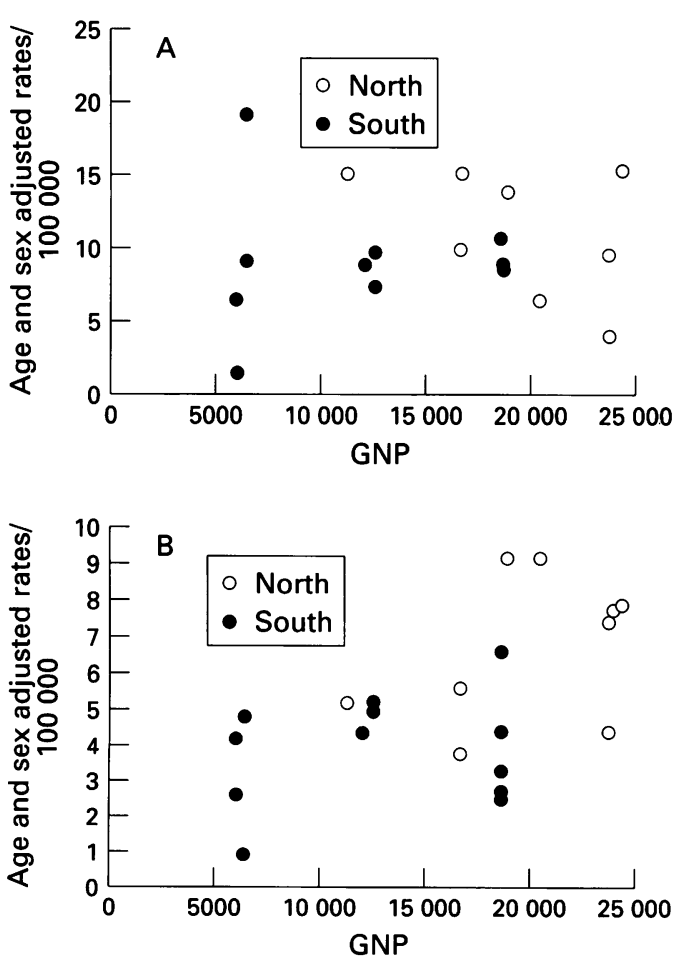

Figure 2: Centre specific age and sex adjusted incidence rates per 100000 for ulcerative colitis including proctitis (UC) and Crohn's disease versus Gross National Product (GNP).
Iceland and Heraklion (Crete, Greece) and the low incidence of CD in Ioannina (north west Greece), the second confirming what was found previously in a retrospective study. ${ }^{28}$ To what extent, if at all, can these findings be explained by differences in the ascertainment of cases between centres? Case ascertainment is dependent on the symptom threshold at which people within a population seek medical advice, access to and availability of specialist care, the sensitivity and specificity of any investigation, and the completeness of search for newly diagnosed cases. The severity of IBD varies greatly and cases with few or no symptoms are not uncommon. ${ }^{29}$ For this reason, patients who were asymptomatic or diagnosed as a result of any screening activity were excluded. Analysis of the presenting symptoms such as bowel frequency, rectal bleeding, weight loss, and abdominal pain showed little overall difference in severity of disease for patients in the northern and southern centres.

Likewise the frequency with which the various diagnostic investigations were performed did not seem to vary between centres. Throughout the two years of the study vigorous efforts were made to recruit all eligible patients; to this end all centres made regular contact with general practitioners and other specialists, 18 centres arranged meetings for their general practitioners, and 17 carried out regular searches of endoscopy and pathology records. Moreover, major differences in case ascertainment do not readily account for areas with a high or low incidence of one disease in the presence of an average incidence of the other as was found in Ioannina (north west Greece), Heraklion (Crete, Greece), and Amiens (north west France).

It is possible that the smaller than expected difference in north-south incidence of IBD found in the present study results from rates in some areas of Europe increasing more rapidly than in others. Several centres in northern Europe reported considerable increases in incidence of CD during the 1950s and 1960s whereas the latest studies have suggested that the increase in incidence of CD in the north has slowed or plateaued. ${ }^{16}{ }^{19}{ }^{30-32}$ Until recently, there were few studies from southern Europe and interpretation of these have been hampered by the problems mentioned above. Two studies from central Italy that examined the incidence of IBD during the 1970s and 1980 s found a roughly threefold increase in the incidence of both UC and CD. ${ }^{14} 33$ In addition, a prospective study of incidence of 
IBD in Zagreb between 1980 and 1990 disclosed an extremely low annual incidence of both UC ( 1.5 per 100000$)$ and CD (0.7 per 100000 ) in neighbouring Yugoslavia. ${ }^{35} 36$

Further evidence that might support the suggestion that the incidence of IBD is changing across Europe is the emergence of differences in age specific incidence of UC in men and women. Many previous studies have shown that in both sexes incidence of UC peaks in early adult life, sometimes with a second lower peak around the age of $65 .{ }^{37} 38$ However, more recent studies have shown less pronounced peaks in age specific incidence in men but not women. ${ }^{6161739}$ In the present study, overall age specific rates of UC among men showed little variation whereas those for women declined with increasing age. This is the first study large enough to show this difference clearly and for it to be significant.

In conclusion, this study suggests a modest excess of incidence of IBD in northern Europe. The magnitude of the observed excess for both conditions is less than expected on the basis of previous studies. This may reflect recent increases in the incidence of IBD in southern Europe whereas those in the north may have stabilised. The aetiology of these conditions is unclear and it is therefore difficult to explain the patterns found. That similar north-south gradients in incidence have also been documented in the United States ${ }^{40}$ suggests that several factors may be involved, including climate, diet, economic wealth, and development or genetic susceptibility. The collaborative network and the baseline data established under this study provides the framework for further studies to monitor the incidence of IBD, particularly in the low incidence areas, and to examine putative environmental factors around Europe.

\section{Appendix}

EC-IBD STUDY PARTICIPANTS (CENTRE, STUDY AREA AND STUDY AREA POPULATION, INVESTIGATORS):

\section{Northern Europe}

1 Reykjavik (Iceland - the whole country - population 195 467): Dr Sigurdur Björnsson, Dr Jóhann H Jóhannsson, Dr Einar Oddsson, Department of Medicine, Reykjavik City and University Hospitals, Iceland.

2 Oslo (south eastern Norway including Oslo population 806 898): Dr Bjørn Moum, Dr Morten Vatn, Dr Erling Aadland, Dr Olav Fausa, Dr Idar Lygren, Dr Jostein Sauar, Dr Tom Schulz, Dr Njaal Stray, Dr Rolf Stave, Medical Department A, Rikshospitalet University, Ullevål University, Telemark Central, Aust Agder Central, Diakonhjemmets and Lovisenberg Hospitals, Norway.

3 Copenhagen (Copenhagen County - population 459 125): Dr Ebbe Langholz, Dr Vibeke Binder, Dr Peter Vedtofte, Dr Jesper Sonne, Medical Departments $\mathrm{C}$ and F, Herlev, Glostrup and Gentofte Hospitals, Copenhagen, Denmark.

4 Dublin (Eastern Health Board including Dublin population 928 619): Dr Rosemary Collins, Professor Colm O'Morain, Department of Gastroenterology, Meath and Adelaide Hospitals, Dublin, Ireland.

5 Leicester (Leicester City - population 211 159): Dr John Mayberry, Mrs Irene Carr, Department of Gastroenterology, Leicester General Hospital, Leicester, UK.
6 Maastricht (South Limburg - population 535 683): Dr Maurice Russel, Professor Reinhold Stockbrügger, Department of Gastroenterology, Academisch Ziekenhuis Maastricht, The Netherlands.

7 Essen (Cities of Essen and Mülheim-Ruhr Area population 698784): Professor Harald Goebell, Dr Bettina Katschinski-Breuer, Department of Gastroenterology, Universitätsklinikum Essen, Germany.

8 Amiens (Department of Somme - population 437 742): Professor Jean-Louis Dupas, Department of Hepatogastroenterology, Centre Hospitalier Universitaire Amiens, France.

\section{Southern Europe}

9 Milan (Unita' Sanitaria Locale 1 including Varese - population 169 830): Professor Paolo Bianchi, Dr T Ranzi, Dr M C Campanini, Dr M Curzio, Dr R Gullotta, Department of Gastroenterology, University of Milan, Italy.

10 Milan (Unita' Sanitaria Locale 51 and 53 including Crema - Cremona - population 251 328): Professor Paolo Bianchi, Dr P Bodoni, Dr P Politi, Dr G Lupinacci, Dr A Zambelli, Department of Gastroenterology, Ospedale di Cremona et OM Crema, Italy.

11 Reggio Emilia (Reggio Emilia - population 370 905): Dr Giovanni Fornaciari, Dr Marina Beltrami, Dr Maria Grazia Mortilla, Dr Franco Nicoli, Dr Luigi Serra, 3rd Department of Internal Medicine, Arcispedale S Maria Nuova, Reggio Emilia, Italy.

12 Florence (Metropolitan Florence - population 539 833): Dr Giacomo Trallori, Dr Andrea Bonanomi, Dr Guiseppe d'Albasio, Professor Franco Pacini, Division of Gastroenterology, Policlinico di Careggi, Firenze, Italy.

13 Vigo (Vigo Health Area - population 413 830): Dr Victor Ruiz Ochoa, Dr Ana de la Fuente, Dr Francisco Tardáguila, Dra Dolores Rodriguez, Dr Santos Pereira, Dra Mercedes Butrón, Dra Margarita Cueto, Dr Luis Alvarez-Cervea, Dr Juan Clofent, Dr Juan R Pineda, Departments of Digestive Diseases, Povisa Policlinico Vigo, Hospital Xeral-Cies and Hospital Meixoeiro, Vigo, Spain.

14 Sabadell (Sabadell Health Area - population 287 714): Dr Enric Brullet, Dr Xavier Bonfill, Dr Gerard Urrútia, Departments of Endoscopy and Epidemiology, Consorci Hospitalari Parc Tauli, Sabadell, Spain.

15 Porto (District of Braga - population 200156 ): Professor Fernando Tavarela Veloso, Dr Reinaldo Noronha, Department of Gastroenterology, Hospital S Joao, Porto and Hospital de San Marcos, Braga, Portugal.

16 Ioannina (Epirus - population 205 798): Dr Epameinondas Tsianos, Georgios Dalekos, Department of Internal Medicine, The University of Ioannina, Greece.

17 Lisbon (Almada, Seixal, Sesimbra - population 238 729): Professor Estela Monteiro, Drs Joao Freitas, Paula Borralho, F Cunha Leal, C Soares, P Martins, M Dupond, Department of Medicine II, Hospital Universitario de Santa Maria, Lisbon, and Department of Gastroenterology and Pathology, Almada Regional Health Department, Portugal.

18 Palermo (Palermo - population 111 894): Dr Mario Cottone, Dr G Filippazzo, Dr Rita Ayala, Department of Medicine, Ospedale "V Cervello", Palermo, Italy. 19 Heraklion (Heraklion - population 181222 ): $\mathrm{Dr}$ Joanis Mouzas, Professor Orestes Manousos, Department of Gastroenterology, University General Hospital Heraklion, Greece.

20 Beer Sheva (Beer Sheva - population 234 500): Professor Selwyn Odes, Gastroenterology Unit, Soroka University Hospital, Beer Sheva, Israel.

\section{STUDY COORDINATION}

\section{Study coordinator}

Dr Mark van Blankenstein, Division of Gastroenterology, Department of Internal Medicine II, University Hospital, Rotterdam "Dijkzigt". 
Principal investigator and scientific director

Dr Shiva Shivananda, Division of Gastroenterology, Department of Internal Medicine II, University Hospital, Rotterdam "Dijkzigt".

Data manager

Dr Ron Brower, Medical Computing Consultants, Rotterdam.

Coordination secretary

Ms Jo-Anne Campbell, Division of Gastroenterology, Department of Internal Medicine II, University Hospital, Rotterdam "Dijkzigt".

\section{SCIENTIFIC ADVISORS}

Clinical gastroenterology

Professor John E Lennard-Jones, Department of Gastroenterology, St Mark's Hospital, London.

\section{Epidemiology}

Sir Richard Doll, Clinical Trials Service Unit, Radcliffe Infirmary Oxford. Dr Anders Ekbom, Cancer Epidemiology Unit, University Hospital Uppsala. Dr Richard F Logan, Department of Public Health and Epidemiology, Queen's Medical Centre, Nottingham. Pathology

Dr Ashley B Price, Department of Cellular Pathology, Northwick Park Hospital, London.

Statistical analysis

Dr Lucy Carpenter, Department of Public Health and Primary Care, University of Oxford. Miss Nicola Fear, ICRF Cancer Epidemiology Unit, Gibson Building, Radcliffe Infirmary, Oxford.

Coordination of the EC-IBD Study was financially supported by Biomed I programme of the Commission of the European Communities with additional support for the meetings in different parts of Europe from Astra (Sweden), Bracco (Italy), Falk Foundation (Germany), and Pharmacia (Sweden). We thank Sir Richard Doll and Professor Martin Vessey for help in design and conduct of the study, and for their review with Dr Valerie Beral of the manuscript.

1 Orholm M, Munkholm P, Langholz E, Haagen Nielsen O, Sørensen TIA, Binder V. Familial occurrence of inflammatory bowel disease. $N$ Engl $f$ Med 1991; 324: 84-8.

2 Lanfranchi GA, Mechelini A, Brignola C, et al. Uno studio epidemiologico sulle malattie inflammatorie intestinali nella provincia de Bologna. Giornale di Clinica Medica 1976; 57: 235-45.

3 Hellers G. Crohn's disease in Stockholm county 1955-74: a study of epidemiology, results of surgical treatment and long term prognosis. Acta Chir Scand 1979; (suppl 490): $1-84$

4 Paredes JG, Garcia JMP. Crohn's disease in the central area of Spain. In: Peña AS, Weterman IT, Booth CC, Strober W, eds. Developments in gastroenterology. 1. Recent $1981 ; 168-73$.

5 Binder V, Both H, Hansen PK, et al. Incidence and prevalence of ulcerative colitis and Crohn's disease in the county of Copenhagen, 1962-78. Gastroenterology 1982; 83: $563-8$.

6 Sinclair TS, Brunt PW, Mowat NAG. Non-specific proctocolitis in north-eastern Scotland: a community proctocolitis in north-eastern Scotla
study. Gastroenterology 1983; 85: $1-11$.

7 Nordenvall B, Berglund M, Bostrom D, Berglund M, Monsen U, Nordenstrom J, et al. Epidemiology of ulcerative colitis in Stockholm County. Scand $f$ Gastroenterol 1985; 20: 783-90.

8 Ruiz V, Potel J. Crohn's disease in Galicia, Spain: 1968-1982. Frontiers in Gastrointestinal Research 1986; 11: 94-101.

9 Shivananda S, Peña AS, Nap M, et al. Epidemiology of Crohn's disease in Regio Leiden, The Netherlands. A population study from 1979-83. Gastroenterology 1987; 93: 966-74.

10 Shivananda S, Peña AS, Mayberry JF, et al. Epidemiology of proctocolitis in the region of Leiden, The Netherlands. A population study fron.

11 Haug K, Schrumpf E, Barstad S, Fluge G, Halvorsen JF, and the Study Group of Inflammatory Bowel Disease in Western Norway. Epidemiology of ulcerative colitis in western Norway. Scand f Gastroenterol 1988; 23: 517-22.
12 Björnsson S. Inflammatory bowel disease in Iceland during a 30 year period, 1950-79. Scand $\mathcal{F}$ Gastroenterol 1989; 24 (suppl 170): 47-9.

13 Roin F, Roin J. Inflammatory bowel disease of the Faroe Islands, 1981-8. Scand $\mathcal{F}$ Gastroenterol 1989; 24 (suppl 170): 44-6.

14 Trallori G, d'Albasio G, Palli D, et al. Epidemiology of inflammatory bowel disease over a 10 year period in Florence (1978-87). Ital $\mathcal{f}$ Gastroenterol 1991; 23: Florence

15 Cottone $M$, Cipolla C, Orlando A, et al. Epidemiology of Crohn's disease in Sicily. A hospital incidence study from 1987-9. Eur f Epidemiol 1991; 7: 636-40.

16 Ekbom A, Helmick C, Zack M, Adami HO. The epidemiology of inflammatory bowel disease: a large population-based study in Sweden. Gastroenterology 1991; 100: $350-8$.

17 Langholz E, Munkholm P, Haagen Nielsen O, Kreiner S, Binder V. Incidence and prevalence of ulcerative colitis in Copenhagen County from 1962-87. Scand $\mathcal{f}$ Gastroenterol 1991; 26: 1247-56.

18 Kyle J. Crohn's disease in the northeastern and northern isles of Scotland: an epidemiological review. Gastroenterology 1992; 103: 392-9.

19 Munkholm P, Langholz E, Haagen Nielsen O, Kreiner S, Binder V. Incidence and prevalence of Crohn's disease in the County of Copenhagen, 1962-87: a sixfold increase in incidence. Scand $\mathcal{F}$ Gastroenterol 1992; 27: 609-14.

20 Shivananda S, Hordijk ML, Peña As, Mayberry JF, van Blankenstein M. Proceedings of the first European community workshop on inflammatory bowel disease. Scand $\mathcal{f}$ Gastroenterol 1989; 24 (suppl 170): 1-101.

21 European Community initiative on inflammatory bowel disease. Lancet 1988; ii: 1321.

22 Lennard-Jones JE. Classification of inflammatory bowel disease. Scand 7 Gastroenterol 1989; 24 (suppl 170): 2-6.

23 United Nations. World population prospects 1990. New York: United Nations, 1991.

24 Breslow NE, Day NE. Statistical methods in cancer research. Vol II. The design and analysis of cohort studies. Lyon: International Agency for Research on Cancer, 1987: 58-9. (Sci publ No 82.)

25 EGRET reference manual. Seattle: Statistics and Epidemiology Research Corporation and Cytel Software Corporation, 1990.

26 Probert CSJ, Jayanthi V, Pinder D, Wicks AC, Mayberry JF. An epidemiological study of ulcerative proctocolitis in Indian migrants and the indigenous population of Indian migrants and the indigenous

27 World Development Report. Investing in health - world development indicators. New York: Oxford University Press, 1993.

28 Tsianos EV, Masalas CN, Merkouropoulos M, Galekos $\mathrm{GN}$, Logan RFA. Incidence of inflammatory bowel disease in north west Greece: rarity of Crohn's disease in an area where ulcerative colitis is common. Gut 1994; 35: 369-72.

29 Mayberry JF, Ballantyne KC, Hardcastle JD, Mangham, Pye G. Epidemiological study of asymptomatic inflammatory bowel disease: the identification of cases during a screening programme for colorectal cancer. Gut 1989; 30: 481-3.

30 Fellows IW, Freeman JG, Holmes GKT. Crohn's disease in the city of Derby, 1951-85. Gut 1990; 31: 1262-5.

31 Lee FI, Nguyen-Van-Tam JS. Prospective study of incidence of Crohn's disease in northwest England: no increase since the late 1970s. Eur $\mathcal{F}$ Gastroenterol Hepatol 1994; 6: 27-31.

32 Thomas GAO, Millar-Jones D, Rhodes J, Roberts GM, Williams GT, Mayberry JF. Incidence of Crohn's disease in Cardiff over 60 years: $1986-90$ an update. Eur 7 Gastroenterol Hepatol 1995; 7: 401-5.

33 Trallori G, Bonanomi AG, Bardazzi G, et al. Incidence and prevalence of inflammatory bowel disease in Florence from 1978-92. Gastroenterology 1995; 108: A930.

34 Tragnone A, Hanau C, Bazzocchi G, Lanfranchi GA. Epidemiological characteristics of inflammatory bowel disease in Bologna, Italy - incidence and risk factors. Digestion 1993; 54: 183-8.

35 Vucelic B, Korac B, Sentic M, et al. Epidemiology of Crohn's disease in Zagreb, Yugoslavia: a 10-year prospective study. Int f Epidemiol 1991; 20: 216-20.

36 Vucelic B, Korac B, Sentic M, et al. Ulcerative colitis in Zagreb, Yugoslavia: incidence and prevalence 1980-1989. Int $₹$ Epidemiol 1991; 20: 1043-7.

37 Calkins BM, Mendeloff AI. Epidemiology of inflammatory bowel disease. Epidemiol Rev 1986; 8: 60-91.

38 Langman MJS. Chronic non-specific inflammatory bowel disease - ulcerative colitis. In: Langman MJS, ed. The epidemiology of chronic digestive disease. London: Edward epidemiology of chromic

39 Gower-Rousseau C, Salomez J-L, Dupas J-L, et al. Incidence of inflammatory bowel disease in northern France (1988-90). Gut 1994; 35: 1433-8.

40 Sonnenberg A, McCarty DJ, Jacobsen SJ. Geographic variation of inflammatory bowel disease within the United States. Gastroenterology 1991; 100: 143-9. 